\title{
Quality management in the cardiac catheterization laboratory
}

\author{
Shady Henien, Herbert D. Aronow, J. Dawn Abbott \\ Division of Cardiology, Warren Alpert Medical School, Brown University, Providence, RI, USA \\ Contributions: (I) Conception and design: All authors; (II) Administrative support: All authors; (III) Provision of study materials or patients: All \\ authors; (IV) Collection and assembly of data: All authors; (V) Data analysis and interpretation: All authors; (VI) Manuscript writing: All authors; (VII) \\ Final approval of manuscript: All authors. \\ Correspondence to: Shady Henien, MD. Division of Cardiology, Warren Alpert Medical School, Brown University, Providence, RI, USA. \\ Email: Shady_Henien@Brown.edu.
}

\begin{abstract}
The development of quality assurance (QA) and quality improvement (QI) initiatives have paralleled the expansion and proliferation of cardiac catherization laboratories. Quality cardiovascular care aims to deliver high standards for patient safety by developing processes and systems to optimize patientteam interactions. Quality can be assessed at the individual operator, team, program, facility or system level. Cardiovascular societies and organizations have developed national registries to help institutions benchmark their process and outcomes against national standards. Various quality measurement techniques are available to assess current performance and identify opportunities for improvement. Appropriate use criteria (AUC) for revascularization were implemented to serve as a QA measure to examine the use of medical procedures. In today's value-based payment systems-focused healthcare climate, quality metrics are followed closely by many payors. In this review, the framework for quality in the cardiac catheterization laboratory and tools to achieve continuous quality improvement (CQI) are discussed.
\end{abstract}

Keywords: Quality assurance (QA); quality improvement (QI); cardiac catheterization laboratory; continuous quality improvement (CQI); registry

Submitted Sep 30, 2019. Accepted for publication Dec 16, 2019.

doi: $10.21037 /$ jtd.2019.12.81

View this article at: http://dx.doi.org/10.21037/jtd.2019.12.81

\section{Introduction}

The development of quality assurance (QA) and quality improvement (QI) programs has paralleled the proliferation of cardiac catheterization laboratories (Cath labs), and the expansion of procedural indications including for complex coronary, peripheral endovascular, and structural heart procedures (1). While Cath lab procedures can reduce morbidity and/or mortality, there is a multitude of reasons for the emphasis on quality including the high volume and cost of procedures, the potential for serious complications, and variability in care. The Institute of Medicine has defined quality as "the degree to which health services for individuals and populations increase the likelihood of desired health outcomes and are consistent with current professional knowledge" (2). In the Cath lab, quality is often viewed as performing the right procedure, on the right patient, at the right time (3). This review will identify and describe QI frameworks; highlight quality registries; identify components of an effective Cath lab QI team, and list metrics to use when measuring QI within the Cath lab.

\section{Donabedian framework and quality measures}

Evaluating the quality of care in the cardiac Cath lab can be approached using the Donabedian model, which encompasses a triad of measures: structure, process, and outcome (4). The structure is the context in which care is delivered such as the hospital or organization. This comprises the regulatory and compliance requirements which include peer review, credentialing criteria, continuing medical education requirements, registry participation 


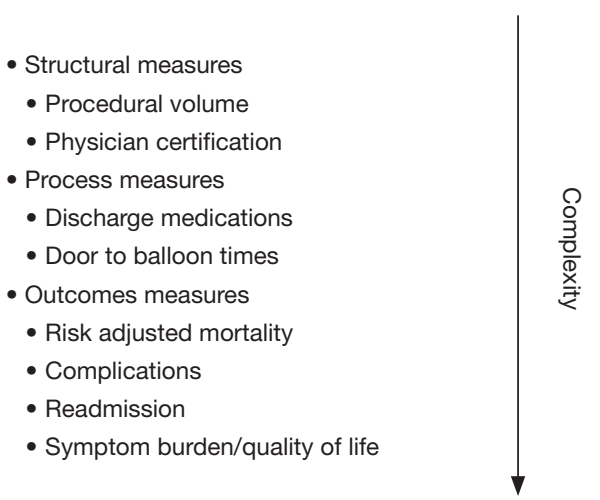

Figure 1 Donabedian framework applied to the Cath lab.

and reporting (5). The physical structure of the Cath lab may vary among centers regarding a number of procedure rooms, location of cineangiographic equipment in relation to the control room, and other design variables (6). These physical variables, and other structural measures such as procedural volume, are relatively easy to measure but do not necessarily correlate with care quality (Figure 1). Process metrics are more complex and assess care through activities that occur at the level of the patients and providers. Numerous process metrics are relevant to the Cath lab such as: care algorithms for ST segment myocardial infarction (STEMI) and cardiac arrest. Process measures capture door-to-balloon time for STEMI, evidence-based discharge medication, and referral for cardiac rehabilitation when appropriate (5). The advantage of process measures is that they have clear definitions, the minimal incremental cost to collect, and accountability can be assigned. However, drawbacks include a ceiling effect, potentially excluded populations, and the possibility that they may not correlate with outcomes. Outcome measures focus on how the care delivered is reflected in the patient's health. Many of these complex measures must be risk-adjusted and include mortality, bleeding, and acute kidney injury (5,7-10). Other examples of outcomes metrics include patient experience, health status (functional status and quality of life), and cost. While outcome measures are the most meaningful, they must be interpreted with caution as misinterpretation may have unintended consequences such as shifting the accessibility of care or increasing risk aversion.

The National Quality Forum (NQF) is a non-profit organization that aims to improve the quality of care through performance measures and standards (11). NQF endorses national consensus standards that can be used for measuring performance and public reporting. Due to the focus put on these metrics, they are selected based on validity, reliability, the ability for risk adjustment and that they are practical to measure. In addition, if variation exists, the measure should be modifiable with QI methods. Risk-adjusted in-hospital mortality in all percutaneous coronary intervention (PCI) patients is a commonly reported performance measure. Cardiovascular societies such as the American College of Cardiology (ACC) and Society for Cardiovascular Angiography and Interventions (SCAI) are committed to assisting physicians and hospitals in providing quality cardiovascular care. Quality competency statements written by physician experts and endorsed by medical societies and organizations serve to inform physicians, Cath lab leadership, and payors about quality related topics. Such statements have described the components of a quality curriculum for trainees, the development of risk-adjusted models for PCI outcomes, and updates on public reporting (12-14).

\section{Continuous quality improvement (CQI)}

The CQI model is proactive and dynamic and focuses on data and statistics. In the Cath lab, the intent is to reduce variation and improve patient safety, quality, and efficiency through continuous assessment (15-17). Contrary to the traditional QA model that identified outliers and used standards for comparisons, CQI focuses on the improvement of performance using the framework of the structure, process, and outcome measures $(1,18)$. CQI leadership teams that include physicians, Cath lab staff, and administrators must ensure the proper collection and validity of data $(16,17)$. These data must be synthesized into a format that can be used to identify opportunities for improvement. Cath lab leadership teams then identify a problem that is measurable with valid quality indicators (Tables 1-3) (19). Within the institution, over time the indicator is tracked and compared to national benchmarks where available. Interventions are then developed to address the problem and follow up data collected to determine if there is a positive change in the indicator (19). This process is not intended to be punitive, but constructive. Attention to detail on systematic versus individual operator deficiencies is required. The aim is to strengthen the program to ensure patient safety (20).

An example of a CQI project is a process for radiation safety. Operators and all Cath lab team members should wear radiation dosimetry badges, properly placed, during 
Table 1 Examples of trackable quality indicators in the cardiac Cath lab

\begin{tabular}{lll}
\hline Quality indicators & Cardiac procedural adverse event & Systemic adverse event \\
\hline Mortality: in-hospital and 30 days & No reflow from embolization & Neurologic event \\
Unplanned coronary artery bypass graft surgery & Coronary perforation & Acute kidney injury \\
Incidence of non-obstructive coronary artery disease & Cardiac tamponade & Radiation injury \\
Missed door-to-balloon time & Stent thrombosis & Bleeding \\
Wrong patient & Access site vascular injury & Infection \\
\hline
\end{tabular}

Table 2 Examples of QI techniques used in the Cath lab

\begin{tabular}{ll}
\hline Technique & Cath lab QI \\
\hline PDSA cycles & Radiation exposure \\
RCA & Medication errors \\
FMEA & Contrast induced nephropathy \\
TQM & Cross functional teams \\
Lean production & Vascular access \\
DMAIC & ST elevation myocardial infarction \\
DMADV & On-time patient arrival to Cath lab \\
\hline
\end{tabular}

QI, quality improvement; PDSA, plan-do-study-act; RCA, root cause analysis; FMEA, failure modes and effects analysis; TQM, total quality management; DMAIC, define, measure, analyze, improve, control; DMADV, define, measure, analyze, design, verify.

every case. The initial structure may include assuring proper testing of all lead gear to ensure safety compliance. This includes thyroid shields, lead aprons, eyewear, table suspended drapes, and shields (21). Regular assessment of the radiation dosimetry badges should be checked. Physicians who have higher than average radiation doses per month should be notified and reason for higher than average exposure, such as high case volume or poor radiation reduction practice, assessed. Once the issues are identified, adequate corrective processes can be put in place. This may include training the individual on radiation mitigation techniques such as optimal table and image intensifier height and shielding, use of less angulated views and lower magnification, lower frame rates, use of the fluoroscopy save rather than cineangiography, etc. Additional measures can be implemented including the use of radiation pads to reduce scatter, tubing extension and autoinjectors. After these processes are instituted the dosimetry badge should be rechecked after 1 month to monitor for outcome changes in radiation doses. This process should be modified as
Table 3 ACE Cath lab standards

\begin{tabular}{l}
\hline Cath lab standards \\
\hline Facility \\
Equipment \\
Leadership structure \\
Physician extenders and cardiology fellows \\
Nurses \\
Technologists \\
Reporting of results \\
Procedure indications and consent \\
Procedure preparation and conduct \\
Patient outcomes \\
QA \\
Radiation safety \\
\hline ACE, Accreditation for Cardiac Excellence; QA, quality \\
assurance.
\end{tabular}

needed until an acceptable outcome is attained. The CQI methodology ensures a systematic approach to attaining the desired outcome.

\section{QA/QI tools}

\section{Registries}

The American College of Cardiology Foundation (ACCF) National Cardiovascular Data Registry (NCDR) is a group of data registries developed to assist hospitals and healthcare providers in measuring, benchmarking and improving cardiovascular care (22). Several of the registries are focused on care delivered in the Cath lab (Figure 2) and institutions performing these procedures should collect and submit data to these registries. The NCDR started in 


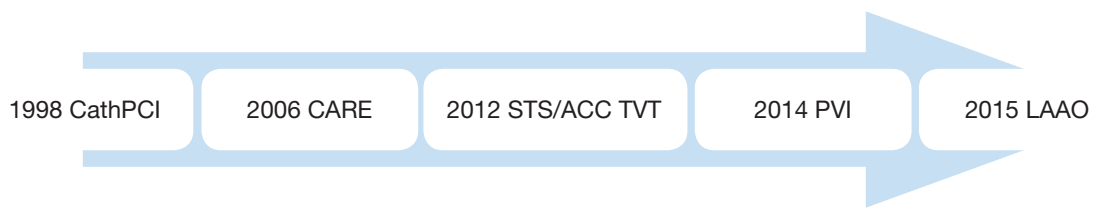

Figure 2 Timeline of launching of Cath lab based NCDR registries. NCDR, National Cardiovascular Data Registry; PCI, percutaneous coronary intervention; STS, Society of Thoracic Surgeons; ACC, American College of Cardiology; TVT, Transcatheter Valve Therapy; PVI, Peripheral Vascular Intervention; LAAO, Left Atrial Appendage Occlusion.

1997 and the CathPCI Registry was the first to be launched with over 17 million records collected by 2014 (17). SCAI collaborates with the ACCF on the registry effort $(12,13)$. The CathPCI Registry captures patient demographics, baseline characteristics, treatments and outcomes following diagnostic Cath and/or PCI procedures. The NQF has endorsed elements of the CathPCI Registry such as composite discharge medications (i.e., dual antiplatelet therapy and statin), PCI risk-adjusted mortality, and hospital 30-day risk-standardized readmission rates (23). The CathPCI Registry offers a quarterly review of the facility's performance, based on the proceeding four quarters, compared to all other facilities and those with similar procedural volumes, for key metrics (23). As of 2014, 90\% of PCI capable hospitals in the US used the registry with the majority submitting both diagnostic and interventional procedures (24). Individual operators practicing at registry sites, by using their unique national provider identifier (NPI) number, also have access to a physician dashboard. A physician specific report with select quality metrics is generated based on the procedures performed.

The Society of Thoracic Surgeons (STS)/ACC Transcatheter Valve Therapy (TVT) Registry was launched in 2012 with the initial approval of transcatheter aortic valve replacement (TAVR) in the US (25). The STS/ ACC TVT Registry is a collaboration between the STS and ACC to provide quality metrics related to TAVR and transcatheter mitral valve repair (TMVR) in collaboration with the Federal Drug Administration (FDA), Centers for Medicare and Medicaid Services (CMS), SCAI, and American Association for Thoracic Surgery (26). Important to hospital finances, participation in the TVT Registry meets the national coverage decision requirements for CMS. The Peripheral Vascular Intervention (PVI) Registry measures outcomes for patients undergoing percutaneous treatment for peripheral vascular disease and carotid interventions (carotid endarterectomy and stenting) (27). The PVI Registry provides quarterly benchmark reports comparing an institution to its peer facilities. Cardiovascular procedures are also included in the Society for Vascular Surgery Vascular Quality Initiative (SVS-VQI) which collects in-hospital and 9-20 months follow-up (28). This registry includes biannual regional meetings to allow Cath lab members and quality officers to meet and share information about vascular care. The Left Atrial Appendage Occlusion (LAAO) Registry, launched in 2015 with FDA approval of the Watchman LAAO device, also meets registry requirements for CMS coverage and offers outcome and cost effectiveness data among national healthcare facilities (29).

In summary, the family of NCDR registries serves as a resource for Cath labs in the US. The repository of welldefined clinical data and risk-adjusted outcomes can be used to identify and close gaps in quality of care, reduce variation and disparities in care, improve efficiency and lower cost of care. Most Cath labs use NCDR Registries for CQI. The Registries have also contributed to device surveillance, outcomes research and clinical guideline development.

\section{Peer review}

Random cases from individual operators should be selected for peer-review on a regular basis. Individual and group outcomes should be compared with national benchmarks $(15,17,19)$. Peer-reviewed cases as outlined by the Intersocietal Accreditation Commission on Standards and Guidelines for Cardiovascular Catherization Accreditation must include a minimum of four cases per procedure type: adult diagnostic Cath, PCI, valve interventions, structural heart interventions, complex adult congenital heart disease, and pediatric cardiovascular Cath every 6 months (15). Discussions and findings in peer-reviewed activities are not liable to subpoena.

\section{Morbidity and mortality (MঊM) conference}

$M \& M$ is an opportunity to devote an allotted period of 
time for all members of the care team to discuss cases with adverse outcomes. Cases should be presented with the intent to derive plans and solutions for future system improvement. These conferences should be formally structured to discuss the presentation of the deidentified physician-patient encounter, case-based review focusing on the pertinent labs, electrocardiogram (ECG), imaging findings, system processes, and the outcomes of the encounter. The Association of American Medical Colleges proposed M\&M conference structure includes an introduction of the case; case narrative including pertinent findings from a chart review; a process map; explanation of system theories; QI teaching points; fishbone group interaction to identify factors that led to this outcome; a literature review of this procedure and/or outcome; a proposed action plan to mitigate future adverse outcomes; and a conclusion of the case (30). This is an opportunity for physicians and other Cath lab team members to identify medical errors when they occur, and other variables that can be optimized to improve future care. $M \& M$ should not be used as a platform for accusatory or punitive engagement (31). M\&M conferences should promote a culture of patient safety and open communication among all physicians, caregivers and administrators. Adverse events in patient care usually result from a series of errors within the system (30).

\section{Appropriate use criteria (AUC)}

AUC for revascularization were developed to serve as a QA measure for both under- and over-utilized procedures. Procedures are designated into 1 of 3 categories: appropriate, may be appropriate or rarely appropriate $(15,32)$. In 2009, the ACC and other medical professional societies developed the AUC for coronary revascularization to examine selection criteria for PCI given concerns for overuse (32). The original reports revealed a large variation in nonacute PCI procedures across hospitals $(33,34)$. The most recent PCI appropriateness guidelines were published in 2016 and 2017 for acute coronary syndrome and stable ischemic heart disease, respectively $(32,35)$. In both revisions, clinical scenarios were drafted that mimic daily practice encounters including symptom status, risk of noninvasive findings, and coronary anatomy. Each of the clinical scenarios was independently ranked by a panel that scored them on a scale from 1 to 9 . Scores from 7 to 9 suggest that revascularization is appropriate while scores from 1 to 3 suggest that revascularization is rarely appropriate; scores from 4 to 6 suggest that revascularization may be appropriate for a given clinical scenario. The application of these criteria is utilized in the CathPCI Registry as a process metric. CMS has adopted AUC as a metric to evaluate care, facilities have utilized these criteria to establish protocols, and while not intended or recommended by those who drafted the AUC documents, some payors have used these for preauthorization of procedures, in some cases exacerbating disparities in care (e.g., in New York state Medicaid program). Although the intent of the AUC was not to dictate payment, some payors have established rules that if rarely appropriate procedures were performed that a physician would not be paid. Outliers may need to perform remediation at work, required to perform additional preauthorization for procedures, and receive a reduction in reimbursement.

\section{QI techniques}

There are several wells studied QI techniques that can be used to improve outcomes in the Cath lab including: plando-study-act cycles (PDSA cycles), root cause analysis (RCA), failure modes and effects analysis (FMEA), total quality management (TQM), lean production, and six sigma methodologies of define, measure, analyze, improve, control (DMAIC) and define, measure, analyze, design, verify (DMADV) (12). Table 2 shows the application of QI techniques to Cath lab quality. PDSA cycles aim to use focus groups with stakeholders of the Cath lab team and brainstorm with flow charts about given problems. This technique can be used to evaluate process measures and if best practices are followed such as minimizing radiation exposure to patients and operators, appropriate dosing of procedural antithrombotic therapy, and efficiency in inter-procedural turnover time. RCA is a retrospective analysis quality tool to evaluate past problems via causeand-effect diagrams in order to prevent future problems. This method is generally used to determine the cause of variations in the standard of care (i.e., medication error). FMEA is a prospective measure used to identify system problems that may negatively impact patient safety such as high contrast volume. This helps prevent process failure prior to implantation. TQM promotes quality measurement, leadership, customer orientation, and continuous improvement and generally requires the creation of multidisciplinary teams in the Cath lab. Lean production aims to reduce the cost of the production while ensuring that quality is uncompromised. This can be accomplished through standards for vascular access and closure, and post-procedure 
recovery protocols. Six sigma DMAIC is used for existing projects and DMADV is used for new processes (12).

\section{Cath lab accreditation}

The purpose of Cath lab accreditation is to ensure national quality standards among centers to optimize clinical and operational outcomes. These standards are established by promoting best practices, professional and national practice guidelines, and appropriateness. The essential components of Cath labs include: governance, quality, pre-procedure, peri-procedure, post-procedure, and clinical quality (36). There are currently two nationally recognized Cath lab accreditation programs: ACC CCL $\mathrm{v} 1$ and Accreditation for Cardiac Excellence (ACE). ACE provides accreditation based on the type of procedure being performed (i.e., diagnostic, PCI, EP, PVI) (37). The accreditation process includes an evaluation of written material submitted by the Cath lab by a panel of trained practitioners. Following the application process a panel of physicians determines whether to grant accreditation, provisional accreditation until updates are performed, or denial. Some facilities are required to have an on-site evaluation. These are usually outlier centers when compared to national outcome data. The frequency of reporting accreditation materials to the accreditation body will be determined by the accreditation body based upon past performance and areas of noncompliance. ACE has identified 12 areas of review (Table 3) (38).

\section{Cath lab privileges}

A key role of the CQI process is to inform the clinicianprivileging process (19). The Director of the Cath lab generally oversees the initial and maintenance privileging process at an institution. In addition to board certification, the QI tools discussed above, including peer review and $M \& M$, ensure that individual operators receive an impartial assessment of procedures and their outcomes $(16,17)$. As the types of procedures have expanded beyond PCI in the Cath lab, the qualifications of operators performing novel procedures have evolved. Lab directors must be current on the training and volume requirements to perform endovascular and structural procedures as well. Minimum annual case volume requirement standards (by type of procedure) and assessment of individual risk-adjusted and other adverse outcomes are generally considered in the privilege renewal process $(10,13,39)$.

\section{Structured Cath lab reporting}

A health policy statement from the ACC on structured reporting in the Cath lab was published in 2014 (19). There are several tenants of structured reporting that reflect the quality of care delivered. The reported information must be relevant to clinical care and operational administration, the document clear, concise, organized and reproducible. Elements for determining AUC such as procedural indication and non-invasive testing results, should be included. In order for the document to be brief and thorough, the use of well-defined discrete data elements is required. The free text should be avoided wherever possible. There needs to be consistency among operators and institutions, which can be achieved by the use of vetted standard vocabulary such as defined in the NCDR data dictionary. Templated documents reduce omissions and errors. Cath labs should expect that reports will be used beyond clinical care for reimbursement and reporting.

\section{Public reporting}

Public reporting of outcomes both at the institution and physician level is aimed at improving quality standards, procedure appropriateness, and reducing cost. This system works to provide transparency to process and outcomerelated data to better inform stakeholders including: patients, employers, health plans, physicians, and policymakers with the intent to improve healthcare delivery (14). Currently, public reporting is well established for hospital systems but formats for provider reporting are still evolving. Public reporting initiatives include state initiatives, payor data, business consumer groups, and reports from independent organizations (16,40-52).

Public reporting mandates were created following the passage of the Affordable Care Act in 2010 which tasked the Agency for Healthcare Research and Quality and CMS with responsibility for oversight. Public reporting has resulted in risk-averse case selection for both CABG and PCI procedures $(17,21,53,54)$. The NCDR CathPCI Registry has approved public reporting of the following quality indicators (Table 4) (39).

Maximizing quality is important from a financial premise 
Table 4 NCDR CathPCI registry quality indicators

CathPCl public reporting
Aspirin at discharge
Thienopyridine at discharge
Statins at discharge
Composite discharge medications (aspirin, P2Y12 inhibitor and
statin)
PCl in-hospital risk-adjusted mortality

30-day all-cause risk-adjusted mortality (ST elevation myocardial infarction or cardiogenic shock)

30-day all-cause risk-adjusted mortality (without ST elevation myocardial infarction or cardiogenic shock)

30-day risk-adjusted readmission rates for $\mathrm{PCl}$

NCDR, National Cardiovascular Data Registry; PCI, percutaneous coronary intervention.

given its correlation with positive operating margins. Due to the decline in reimbursement, unfavorable payor mix, patient defaults as a result of large patient deductibles, and uninsured patients, facilities must now transition from a fee-for-service to value-based payment systems (5). The pressure for healthcare operations to reduce costs must not compromise procedure quality and safety. Thirdparty payors are beginning to select preferred providers and organizations that have demonstrated the consistent higher quality of care metrics compared to their peers (5). For example, these payment contracts may be awarded to facilities that have excellent patient satisfaction scores and outcomes. The converse could result in a loss or deselection by payors (50). Facilities should use benchmarking via one of the multitudes of registries to identify areas of improvement compared to national standards.

\section{Quality committees}

The QI oversight committee is responsible for training medical staff, assessment of patient and cardiac Cath lab quality metrics, adherence to National Patient Safety Goals, organizing QI activities, and developing corrective action plans (15). A complete QA/QI committee includes: chair, staff coordinator, and database manager. The QA/ QI committee develops methods for data collection and may focus on areas including: continued education, patient care, system processes, medical guidelines, costrelated items $(1,7,20,55,56)$, review of complications that were not discussed in $M \& M$ conferences, lapses in universal protocol, equipment issues, and door-to-balloon time (19). The chair of the QI committee identifies and reviews concerns regarding the performance of individual operators with respect to professional behavior, judgement, clinical knowledge, complication rates and procedural appropriateness. Quality concerns should be addressed with the operator in confidence with a structured plan and implementation strategy for improvement followed by reassessment (20). The Joint Commission developed the Ongoing Professional Practice Evaluation (OPPE) and Focused Professional Practice Evaluation (FPPE) processes to make physician privilege decisions more objective (57). The OPPE is a screening tool to identify physicians with privileges that have low-quality performance metrics (57). The FPPE is the follow-up process for physicians that were identified during the OPPE process (57). The corrective action plan should be constructive, not be punitive, and should clearly state expected outcomes and targets (19). Outside CQI committees or impartial reviewers can be enlisted to offer additional advice, when appropriate. Penalties resulting in the suspension of privileges should only be considered following the failure of the operator to comply with the action plan.

The QI committee may also focus on the patient experience. Cath lab design quality can be assessed by using an "end-user experience framework" (6). For example, with a patient user-centered goal the comfort of the procedure and transportation are variables. These patientcentered goals can be measured by patient satisfaction scores. Depending on the results, the team can incorporate different tactics to respond to these results by reducing transportation distance, increased frequency of sedation and pain management checks, etc. A physician centeredgoal may include visibility of the monitor, room lighting, tableside ergonomics and set-up, and radiation protection. These can be measured by using surveys, observational studies, and radiation badges.

\section{Summary}

Cath lab QA can focus on a multitude of factors that directly and indirectly impact patient care. Quality is viewed as performing the right procedure, on the right patient, at 
the right time (3). The Donabedian model is an effective framework to use those measures: structure, process, and outcome (4). Multiple professional organizations (i.e., NQF, NCDR, ACE, etc.) are involved in measuring, reporting, and developing national standards for physicians, Cath lab facilities, and payors to use to measure their improvement. Cath lab quality indicators are tracked and compared to national benchmarks. The CQI model aims to optimize processes and outcomes through a rigorous process at all levels of patient and team interactions. Multiple QI frameworks have been discussed to analyze and develop solutions for optimizing quality outcomes (i.e., PDSA and RCA). This QI and assurance initiatives are expected by healthcare stakeholders when assessing the safety, efficacy, and appropriateness of Cath labs which affect reimbursement, accreditation, and public perception. Cath lab public reporting metrics are used to improve quality standards, procedure appropriateness, and reduce cost. The importance of QI is to ensure patient safety and enhance cardiac procedure-related outcomes that will lead to further practice refinements. As we gather more knowledge from clinical research outcomes, we will be better prepared to adjust our quality metrics to benefit our patients. In the value-based payment model, physicians and healthcare systems will be rewarded on how they steward their resources to achieve similar clinical outcomes. Cath labs will be rewarded based on their ability to demonstrate high-quality care through the use of collaborative processes focused on quality outcomes.

\section{Acknowledgments}

Funding: None.

\section{Footnote}

Provenance and Peer Review: This article was commissioned by the Guest Editor (Ion S. Jovin) for the series "Interventional Cardiology" published in Fournal of Thoracic Disease. The article was sent for external peer review organized by the Guest Editor and the editorial office.

Conflicts of Interest: All authors have completed the ICMJE uniform disclosure form (available at http://dx.doi. org/10.21037/jtd.2019.12.81). The series "Interventional Cardiology" was commissioned by the editorial office without any funding or sponsorship. SH reports "other" by owning shares of self-purchased Shockwave stock during the writing of this review article. The other authors have no other conflicts of interest to declare.

Ethical Statement: The authors are accountable for all aspects of the work in ensuring that questions related to the accuracy or integrity of any part of the work are appropriately investigated and resolved.

Open Access Statement: This is an Open Access article distributed in accordance with the Creative Commons Attribution-NonCommercial-NoDerivs 4.0 International License (CC BY-NC-ND 4.0), which permits the noncommercial replication and distribution of the article with the strict proviso that no changes or edits are made and the original work is properly cited (including links to both the formal publication through the relevant DOI and the license). See: https://creativecommons.org/licenses/by-nc-nd/4.0/.

\section{References}

1. Bashore TM, Balter S, Barac A, et al. 2012 American College of Cardiology Foundation/Society for Cardiovascular Angiography and Interventions expert consensus document on cardiac catheterization laboratory standards update: a report of the American College of Cardiology Foundation Task Force on Expert Consensus documents developed in collaboration with the Society of Thoracic Surgeons and Society for Vascular Medicine. J Am Coll Cardiol 2012;59:2221-305.

2. Lohr KN, Schroeder SA. A strategy for quality assurance in Medicare. N Engl J Med 1990;322:707-12.

3. Institute for Healthcare Improvement. Hospital flow professional development program. Available online: http://www.ihi.org/education/InPerson Training/HospitalFlow-Professional-Development-Program/Pages/default. aspx

4. Donabedian A. The quality of care. How can it be assessed? JAMA 1988;260:1743-8.

5. Blankenship JC, Choi JW, Das TS, et al. SCAI/ ACVP expert consensus statement on cardiovascular catheterization laboratory economics: if the cath lab is your home you should understand its finances. Catheter Cardiovasc Interv 2019;94:123-35.

6. Brownlee SA, Whitson PJ, Ibrahim AM. Measuring and improving the design quality of operating rooms. Surg Infect (Larchmt) 2019;20:102-6.

7. Rao SV, McCoy LA, Spertus JA, et al. An updated bleeding model to predict the risk of post-procedure 
bleeding among patients undergoing percutaneous coronary intervention: a report using an expanded bleeding definition from the National Cardiovascular Data Registry CathPCI Registry. JACC Cardiovasc Interv 2013;6:897-904.

8. Tsai TT, Patel UD, Chang TI, et al. Contemporary incidence, predictors, and outcomes of acute kidney injury in patients undergoing percutaneous coronary interventions: insights from the NCDR Cath-PCI registry. JACC Cardiovasc Interv 2014;7:1-9.

9. Chalikias G, Drosos I, Tziakas DN. Prevention of contrast-induced acute kidney injury: an update. Cardiovasc Drugs Ther 2016;30:515-24.

10. Peterson ED, Dai D, DeLong ER, et al. Contemporary mortality risk prediction for percutaneous coronary intervention: results from 588,398 procedures in the National Cardiovascular Data Registry. J Am Coll Cardiol 2010;55:1923-32.

11. National Quality Forum (NQF). About us. Available online: http://www.qualityforum.org/About_NQF/

12. Jennings HS 3rd, Rao SV, Feldman DN, et al. SCAI core curriculum for adult and pediatric interventional fellowship training in continuous quality assessment and improvement. Catheter Cardiovasc Interv 2015;86:422-31.

13. Singh M, Holmes DR, Lennon RJ, et al. Development and validation of risk adjustment models for longterm mortality and myocardial infarction following percutaneous coronary interventions. Circ Cardiovasc Interv 2010;3:423-30.

14. Dehmer GJ, Drozda JP Jr, Brindis RG, et al. Public reporting of clinical quality data: an update for cardiovascular specialists. J Am Coll Cardiol 2014;63:1239-45.

15. Intersocietal Accreditation Commission. The IAC standards and guidelines for cardiovascular catheterization accreditation. 2017:3-83.

16. Accreditation for Cardiovascular Excellence: Quality in Invasive Cardiovascular Care. ACE standards for catheterization laboratory accreditation. 2015:1-22.

17. Brindis RG, Dehmer GJ. Continuous quality improvement in the cardiac catheterization laboratory are the benefits worth the cost and effort? Circulation 2006;113:767-70.

18. Kern MJ. Quality assurance in the Cath lab-what you need to know. Los Angeles: SCAI.

19. Klein LW, Uretsky BF, Chambers C, et al. Quality assessment and improvement in interventional cardiology: a position statement of the Society of Cardiovascular Angiography and Interventions, part 1: standards for quality assessment and improvement in interventional cardiology. Catheter Cardiovasc Interv 2011;77:927-35.

20. Brennan JM, Curtis JP, Dai D, et al. Enhanced mortality risk prediction with a focus on high-risk percutaneous coronary intervention: results from 1,208,137 procedures in the NCDR (National Cardiovascular Data Registry). JACC Cardiovasc Interv 2013;6:790-9.

21. Christopoulos G, Makke L, Christakopoulos G, et al. Optimizing radiation safety in the cardiac catheterization laboratory: a practical approach. Catheter Cardiovasc Interv 2016;87:291-301.

22. Weintraub WS, McKay CR, Riner RN, et al. The American College of Cardiology National Database: progress and challenges. American College of Cardiology Database Committee. J Am Coll Cardiol 1997;29:459-65.

23. Quality Improvement for Institutions. CathPCI Registry. Available online: https://cvquality.acc.org/NCDR-Home/ registries/hospital-registries/cathpci-registry

24. Masoudi FA, Ponirakis A, de Lemos JA, et al. Executive summary: trends in U.S. cardiovascular care 2016 report from 4 ACC national cardiovascular data registries. J Am Coll Cardiol 2017;69:1424-6.

25. The Society of Thoracic Surgeons. STS/ACC TVT Registry. Available online: https://www.sts.org/registriesresearch-center/stsacc-tvt-registry

26. The Society of Thoracic Surgeons; American College of Cardiology. STS/ACC TVT Registry. Available online: https://www.ncdr.com/WebNCDR/tvt/publicpage

27. Quality Improvement for Institutions. The American College of Cardiology's PVI Registry. Available online: https://cvquality.acc.org/NCDR-Home/registries/ hospital-registries/pvi-registry

28. SVS. About: The value of participation in the vascular quality initiative (VQI). Available online: https://www.vqi. org/about/

29. Quality Improvement for Institutions. LAAO Registry. Available online: https://cvquality.acc.org/NCDR-Home/ registries/hospital-registries/laao-registry

30. Walker M, Rubio D, Horstman M, et al. Stop the blame game: restructuring morbidity and mortality conferences to teach patient safety and quality improvement to residents. MedEdPORTAL. 2016;12:10475.

31. Orlander JD, Barber TW, Fincke BG. The morbidity and mortality conference: the delicate nature of learning from error. Acad Med 2002;77:1001-6.

32. Patel MR, Calhoon JH, Dehmer GJ, et al. ACC/AATS/ AHA/ASE/ASNC/SCAI/SCCT/STS 2017 appropriate use criteria for coronary revascularization in patients with 
stable ischemic heart disease: a report of the American College of Cardiology Appropriate use Criteria Task Force, American Association for Thoracic Surgery, American Heart Association, American Society of Echocardiography, American Society of Nuclear Cardiology, Society for Cardiovascular Angiography and Interventions, Society of Cardiovascular Computed Tomography, and Society of Thoracic Surgeons. J Am Coll Cardiol 2017;69:2212-41.

33. Chan PS, Patel MR, Klein LW, et al. Appropriateness of percutaneous coronary intervention. JAMA 2011;306:53-61.

34. Bradley SM, Maynard C, Bryson C. Appropriateness of percutaneous coronary interventions in Washington state. Circ Cardiovasc Qual Outcomes 2012;5:445-53.

35. Patel MR, Calhoon JH, Dehmer GJ, et al. ACC/ AATS/AHA/ASE/ASNC/SCAI/SCCT/STS 2016 appropriate use criteria for coronary revascularization in patients with acute coronary syndromes: a report of the American College of Cardiology Appropriate Use Criteria Task Force, American Association for Thoracic Surgery, American Heart Association, American Society of Echocardiography, American Society of Nuclear Cardiology, Society for Cardiovascular Angiography and Interventions, Society of Cardiovascular Computed Tomography, and the Society of Thoracic Surgeons. J Am Coll Cardiol 2017;69:570-91.

36. Quality Improvement for Institutions. Features and benefits of cardiac Cath lab accreditation. Available online: https://cvquality.acc.org/accreditation/services/CCL/ CCLBenefits

37. Accreditation for Cardiovascular Excellence. Cardiac catheterization accreditation. Available online: http://www. cvexcel.org/DiagnosticCath.aspx

38. Accreditation for Cardiovascular Excellence. Cardiac catheterization standards. Available online: http://www. cvexcel.org/DiagnosticCath/Standards

39. Blankenship JC, Rosenfield K, Jennings HS 3rd. Privileging and credentialing for interventional cardiology procedures. Catheter Cardiovasc Interv 2015;86:655-63.

40. Sanborn TA, Tcheng JE, Anderson HV, et al. ACC/ AHA/SCAI 2014 Health Policy Statement on Structured Reporting for the Cardiac Catheterization Laboratory: a report of the American College of Cardiology Clinical Quality Committee. J Am Coll Cardiol 2014;63:2591-623.

41. Adams JL, Mehrotra A, Thomas JW, et al. Physician cost profiling--reliability and risk of misclassification. N Engl J Med 2010;362:1014-21.

42. The Leapfrog Group. Leapfrog. Available online: https:// www.leapfroggroup.org/
43. Healthgrades. Find a doctor-Doctor reviews-Online doctor appointments. Available online: https://www. healthgrades.com/

44. Catalyst for Payment Reform. Catalyst for Payment Reform. Available online: http://www.catalyze.org/

45. Omoigui NA, Miller DP, Brown KJ, et al. Outmigration for coronary bypass surgery in an era of public dissemination of clinical outcomes. Circulation 1996;93:27-33.

46. Schneider EC, Epstein AM. Influence of cardiac-surgery performance reports on referral practices and access to care. A survey of cardiovascular specialists. N Engl J Med 1996;335:251-6.

47. Narins CR, Dozier AM, Ling FS, et al. The influence of public reporting of outcome data on medical decision making by physicians. Arch Intern Med 2005;165:83-7.

48. Moscucci M, Eagle KA, Share D, et al. Public reporting and case selection for percutaneous coronary interventions. J Am Coll Cardiol 2005;45:1759-65.

49. Moscucci M. ACCF/NCDR Public Reporting Program Requirements. Available online: https://www.ncdr. com/WebNCDR/docs/default-source/ncdr-generaldocuments/accf-public-reporting-program-requirements. pdf?sfvrsn=b394c49f_6

50. Klein LW, Ho KK, Singh M, et al. Quality assessment and improvement in interventional cardiology: a position statement of the Society of Cardiovascular Angiography and Interventions, part II: public reporting and risk adjustment. Catheter Cardiovasc Interv 2011;78:493-502.

51. Brindis RG, Fitzgerald S, Anderson HV, et al. The American College of Cardiology-National Cardiovascular Data Registry (ACC-NCDR): building a national clinical data repository. J Am Coll Cardiol 2001;37:2240-5.

52. Dehmer GJ, Hirshfeld JW, Oetgen WJ, et al. CathKIT: improving quality in the cardiac catheterization laboratory. J Am Coll Cardiol 2004;43:893-9.

53. Naidu SS, Aronow HD, Box LC, et al. SCAI expert consensus statement: 2016 best practices in the cardiac catheterization laboratory: (Endorsed by the cardiological society of india, and sociedad Latino Americana de Cardiologia intervencionista; Affirmation of value by the Canadian Association of interventional cardiologyAssociation canadienne de cardiologie d'intervention). Catheter Cardiovasc Interv 2016;88:407-23.

54. Harold JG, Bass TA, Bashore TM, et al. ACCF/AHA/ SCAI 2013 update of the clinical competence statement on coronary artery interventional procedures: a report of the American College of Cardiology Foundation/American 
Heart Association/American College of Physicians Task Force on Clinical Competence and Training (Writing Committee to Revise the 2007 Clinical Competence Statement on Cardiac Interventional Procedures). J Am Coll Cardiol 2013;62:357-96.

55. Chambers CE. Morbidity and mortality and beyond: assuring quality in cardiac catheterization laboratory quality programs. Circ Cardiovasc Qual Outcomes 2017. doi: 10.1161/CIRCOUTCOMES.117.004001.

Cite this article as: Henien S, Aronow HD, Abbott JD. Quality management in the cardiac catheterization laboratory. J Thorac Dis 2020;12(4):1695-1705. doi: 10.21037/jtd.2019.12.81
56. Gurm HS, Seth M, Kooiman J, et al. A novel tool for reliable and accurate prediction of renal complications in patients undergoing percutaneous coronary intervention. J Am Coll Cardiol 2013;61:2242-8.

57. The Joint Commission. High Reliability Healthcare. Available online: https://www.jointcommission.org/ resources/news-and-multimedia/blogs/high-reliabilityhealthcare/ 